\title{
Genetic diversity and population structure of local and exotic sheep breeds in Jordan using microsatellites markers
}

\author{
Khaleel I. Jawasreh ${ }^{1}$, Mustafa M. Ababneh' ${ }^{2}$, Zuhair Bani Ismail ${ }^{3}$, Abdel Mon'em Bani Younes ${ }^{1}$ and Ibrahem Al Sukhni ${ }^{1}$ \\ 1. Department Animal Production, Faculty of Agriculture, Jordan University of Science and Technology, Irbid, P. O. Box \\ 2210, Jordan; 2. Department of Basic Veterinary Medical Sciences, Faculty of Veterinary Medicine, Jordan University \\ of Science and Technology, Irbid, P. O. Box 2210, Jordan; 3. Department of Veterinary Clinical Sciences, Faculty of \\ Veterinary Medicine, Jordan University of Science and Technology, Irbid, P. O. Box 2210, Jordan. \\ Corresponding author: Khaleel Jawasreh, e-mail: kijawasreh@just.edu.jo \\ Co-authors: ZBI: zuhair72@just.edu.jo, MA: ababnem@just.edu.jo, AMY: abedalmonemby@yahoo.com, \\ IAS: ibrahims@just.edu.jo
}

Received: 18-02-2018, Accepted: 07-05-2018, Published online: 09-06-2018

doi: 10.14202/vetworld.2018.778-781. How to cite this article: Jawasreh KI, Ababneh MM, Ismail ZB, Younes AMB, Al Sukhni I (2018) Genetic diversity and population structure of local and exotic sheep breeds in Jordan using microsatellites markers, Veterinary World, 11(6): 778-781.

\begin{abstract}
Aim: This study was conducted to study the genetic and population structure of local (Awassi) and exotic (Romanov, Charollais, Assaf, and Suffolk) sheep breeds in Jordan using eight microsatellite markers.

Materials and Methods: A total of 125 sheep were used (25 from each breed) in the study. The number of alleles (A), the mean values of observed (Ho) and expected (He) heterozygosity, polymorphism information content (PIC), fixation index as a measure of heterozygote deficiency or excess, and Hardy-Weinberg equilibrium (HWE) were analyzed using PopGen and CERVUS softwares. Nei's standard genetic distances among breeds and dendrogram of unweighted pair group method with arithmetic mean (UPGMA) were calculated and constructed using PopGen software.

Results: A total of 40 alleles were detected with an average number of alleles of 5. The mean Ho value was higher than the mean He value for all breeds. Awassi breed showed the highest average PIC value while Romanov had the lowest. There was a significant $(\mathrm{p}<0.05)$ deviation from HWE at each locus within and between breeds. Deviations from HWE were found to be highly significant for all markers except OARFCP304 locus. The genetic distance estimates revealed a close relationship between Romanov and Charollais and between Awassi and Charollais. In the UPGMA dendrogram, Charollais, Romanov, and Awassi breeds were placed together in one main cluster while Assaf was in a different subcluster. Awassi was placed alone in a second main cluster.
\end{abstract}

Conclusion: Results of this study offer insight toward the genetic conservation of the studied breeds and a base on which breeding plans can be made.

Keywords: genetic diversity, Jordan, microsatellites, sheep breeds.

\section{Introduction}

Sheep raising is considered an important source of livelihood in Jordan [1]. The local sheep breed Awassi is well adapted to the semi-arid conditions of Jordan and is considered the most common of all sheep breeds. It is known to resist many diseases and to produce modest amount of good quality meat and milk. Genetic improvement of Awassi has been practiced using selection and crossbreeding [2]. Several other imported breeds also exist in Jordan such as Assaf, Suffolk, Romanov, and Charollais. Due to indiscriminate breeding practices, a great level of genetic diversity or lack off is expected among all sheep breeds in Jordan.

Microsatellites are commonly used to estimate the genetic diversity among different farm animal

\footnotetext{
Copyright: Jawasreh, et al. Open Access. This article is distributed under the terms of the Creative Commons Attribution 4.0 International License (http://creativecommons.org/licenses/ by/4.0/), which permits unrestricted use, distribution, and reproduction in any medium, provided you give appropriate credit to the original author(s) and the source, provide a link to the Creative Commons license, and indicate if changes were made. The Creative Commons Public Domain Dedication waiver (http:// creativecommons.org/publicdomain/zero/1.0/) applies to the data made available in this article, unless otherwise stated.
}

species $[3,4]$. Several studies had been investigated the genetic diversity, relatedness, gene mapping, and paternity in goats, sheep, and other animals species using microsatellites markers [5-9].

In Jordan, genetic similarity and distance have been reported within and between Awassi sheep lines (Sagri, black face, and Najdi breeds) using random amplified polymorphic DNA markers [10].

The genetic structure, genetic diversity, and relatedness between Awassi sheep and four of the most common imported sheep breeds Assaf, Suffolk, Romanov, and Charollais were never been studied before. Therefore, the aim of this study was to investigate the genetic structure and variability of Romanov, Charollais, Assaf, Awassi, and Suffolk sheep breeds in Jordan.

\section{Materials and Methods}

Ethical approval

All experimental procedures in this study were approved (Approval No. 16/4/21/70) by the Jordan University of Science and Technology Animal Use and Care Committee. 


\section{Animals}

A total of 125 blood samples were collected from five different sheep breeds (25 samples each) including Awassi, Romanov, Charollais, Assaf, and Suffolk. Whole blood was collected by jugular vein puncture using Vacutainer blood collection tubes containing EDTA and stored at $4^{\circ} \mathrm{C}$ until analysis.

\section{DNA extraction}

DNA was extracted from whole blood samples using the E. Z. N. blood DNA extraction kit according to manufacturer's recommendations (Omega Bio-tek, Inc., USA). The extracted DNA was stored at $-20^{\circ} \mathrm{C}$ until further analysis.

\section{Polymerase chain reaction (PCR) procedure}

DNA samples were amplified with eight microsatellite markers (Table-1). The PCR reaction was performed for each locus in $20 \mu$ reactions consisted of $10 \mu \mathrm{l}$ DNase free water, $2 \mu$ l of genomic DNA (20 ng), $2 \mu \mathrm{l}$ of each of forward and reverse primers, and $4 \mu \mathrm{l}$ (5 U/ $\mu 1$ ) of master mix (Hot Firepol, Solis Biodyne, Estonia). The PCR program was carried out at $95^{\circ} \mathrm{C}$ for $5 \mathrm{~min}$, followed by 35 cycles of $95^{\circ} \mathrm{C}$ for $30-45 \mathrm{~s}$, annealing for $30-90 \mathrm{~s}$, extension at $72^{\circ} \mathrm{C}$ for $30-60 \mathrm{~s}$, and final extension at $73^{\circ} \mathrm{C}$ for $5-30 \mathrm{~min}$. After obtaining the targeted fragment of DNA, the PCR products were mixed 1:3 with loading buffer (98\% formamide, $0.09 \%$ xylene cyanole, and bromophenol blue), the mixture of PCR product and loading buffer was denatured at $95^{\circ} \mathrm{C}$ for $5 \mathrm{~min}$, chilled on ice rapidly, and loaded in $12 \%$ polyacrylamide gels (29:1 acrylamide: bis-acrylamide). Alleles that have sizes $<50 \mathrm{bp}$ were visualized using $12 \%$ polyacrylamide gel electrophoresis. The gel was screened by UV illuminator. A 50 bp DNA ladder was used to estimate allele size base pairs (bp).

\section{Genetic data analysis}

The Ho and He, fixation index (Fis) as a measure of heterozygote deficiency or excess, PIC, and Hardy-Weinberg equilibrium (HWE) were analyzed using PopGen [11] and CERVUS software [12]. Nei's standard genetic distances among breeds and dendrogram of unweighted pair group method with arithmetic mean (UPGMA) were calculated and constructed using PopGen software [11,13].

\section{Results}

The total numbers of alleles (A), Ho, He, PIC, and HWE for each of the eight microsatellites used in this study are presented in Table-2. All eight microsatellite loci were successfully amplified and were found polymorphic. A total of 40 alleles were detected. The average number of alleles per locus was 5 . The number of alleles per locus ranged from 3 (ILSTS5 and ILSTS11) to 9 (MAF214). The Ho and He values ranged between 0.68 to 1.00 and 0.55 to 0.86 , respectively. PIC values ranged from 0.44 to 0.84 . There was a significant $(\mathrm{p}<0.001)$ deviation from HWE at each locus within and between breeds. When the HWE test was performed for each individual locus, deviations from the HWE were found to be highly significant for all markers except OARFCP304 locus.

The number of alleles (A), Ho, He, Fis, and PIC for eight microsatellites in Romanov, Charollais, and Suffolk, Awassi, and Assaf sheep breeds are presented in Table-3. The total number of alleles was highest in Awassi (28) followed by Assaf (26), Romanov (25), Charollais, and Suffolk (24). The average number of alleles per breed was 3, 3, 3, 3.5, and 3.3 for Romanov, Charollais, Suffolk, Awassi, and Assaf, respectively. The average Ho value was higher than the He value for all breeds. The average Ho value for overall loci in Romanov, Awassi, Charollais, Suffolk, and Assaf breeds was $0.9,0.9,0.8,0.9$, and 0.9 , respectively. Whereas, the average He for all loci in the five breeds was 0.6, 0.6, 0.6, 0.7, and 0.7 for Awassi, Assaf, Charollais, Suffolk, and Romanov, respectively. The average PIC values in all breeds varied from 0.5 (Romanov) to 0.6 (Awassi). Within loci, OARJMP58 showed the highest PIC value (0.8) in Awassi sheep.

The matrix of Nei's standard genetic distances among the studied sheep breeds is presented in Table-4. There is a close relationship between Romanov and Charollais (0.79). A close relationship was also

Table-1: Sequences of microsatellite marker primers, annealing temperature, and allele size.

\begin{tabular}{|c|c|c|c|}
\hline Locus name & Sequence $5^{\prime}-3^{\prime}$ & Annealing Temperature $\left({ }^{\circ} \mathrm{C}\right)$ & Size (bp) \\
\hline MAF214 & $\begin{array}{l}\text { F: GGGTGATCTTAGGGAGGTITTGGAGG } \\
\text { R: AATGCAGGAGATCTGAGGCAGGGACG }\end{array}$ & 63 & $174-282$ \\
\hline MAF65 & $\begin{array}{l}\text { F: AAAGGCCAGAGTATGCAATTAGGAG } \\
\text { R: CСАСTCСTCСTGAGAATATAACATG }\end{array}$ & 60 & $123-127$ \\
\hline OARAE129 & $\begin{array}{l}\text { F: AATCCAGTGTGTGAAAGACTAATCCAG } \\
\text { R: GTAGATCAAGATATAGAATATITITCAACACC }\end{array}$ & 56 & $133-159$ \\
\hline ILSTS5 & $\begin{array}{l}\text { F: GGAAGCAATGAAATCTATAGCC } \\
\text { R: TGTTCTGTGAGTTTGTAAGC }\end{array}$ & 55 & $174-218$ \\
\hline OARCP34 & $\begin{array}{l}\text { F: GCTGAACAATGTGATATGTTCAGG } \\
\text { R: GGGACAATACTGTCTTAGATGCTGC }\end{array}$ & 54 & $112-130$ \\
\hline OARJMP58 & $\begin{array}{l}\text { F: GAAGTCATTGAGGGGTCGCTAACC } \\
\text { R: CTTCATGTTCACAGGACTTTCTCTG }\end{array}$ & 61 & $145-169$ \\
\hline LSTS11 & $\begin{array}{l}\text { F: GCTTGCTACATGGAAAGTGC } \\
\text { R: CTAAAATGCAGAGCCCTACC }\end{array}$ & 55 & $256-294$ \\
\hline OARFCB304 & $\begin{array}{l}\text { F: CCCTAGGAGCTTTCAATAAAGAATCGG } \\
\text { R: CGCTGCTGTCAACTGGGTCAGGG }\end{array}$ & 61 & $150-188$ \\
\hline
\end{tabular}


found between Awassi and Charollais (0.79). Nei's genetic distance between Romanov and Charollais breeds was similar to the genetic distance between Awassi and Charollais breeds (0.24). The genetic distance between Assaf and Suffolk breeds was 0.53.

In the UPGMA dendrogram (Figure-1), two main clusters and two subclusters were identified. In the main clusters, Charollais, Romanov, and Awassi breeds were placed together while Assaf was in the other subcluster. Awassi was placed alone in the second main cluster.

\section{Discussion}

In this study, the genetic contribution of four exotic sheep breeds (Charollais, Romanov, Assaf, and Suffolk) and their relationship with the local Awassi breed was studied for the $1^{\text {st }}$ time using microsatellite markers. The level of variation depicted by the number of alleles at each locus serves as a measure of the impact of each of the studied breeds on differentiation within livestock populations in Jordan. In this study, the number of alleles per locus was ranged from 3 to 9. Similar results were reported in Muzzafarnagri sheep [5] and Bangladesh sheep [7], while a higher number of alleles was detected in Sinai, Rahmani, and Ossimi breeds in Egypt [9] and Kilakarsal sheep [14]. Variation in allele numbers between studies usually indicates differences in studied breeds and markers

Table-2: Number of alleles (A), observed Ho, expected $\mathrm{He}, \mathrm{PIC}$, and HWE for each of the eight microsatellites.

\begin{tabular}{lccccc}
\hline Locus & A & Ho & He & PIC & HWE \\
\hline ILSTS5 & 3 & 1.00 & 0.61 & 0.53 & $* * *$ \\
ILSTS11 & 3 & 1.00 & 0.64 & 0.57 & $* * *$ \\
OARCP34 & 4 & 1.00 & 0.73 & 0.68 & $* * *$ \\
OARFCP304 & 8 & 0.68 & 0.86 & 0.84 & NS \\
OARJMP58 & 5 & 0.79 & 0.77 & 0.73 & $* * *$ \\
OARAE129 & 4 & 1.00 & 0.55 & 0.44 & $* * *$ \\
MAF214 & 9 & 1.00 & 0.83 & 0.81 & $* * *$ \\
MAF65 & 4 & 1.00 & 0.65 & 0.58 & $* * *$ \\
Mean & 5 & 0.90 & 0.70 & 0.65 & \\
\hline
\end{tabular}

$* * * \mathrm{p}<0.001, \mathrm{NS}=\mathrm{p}>0.05$ (using Bonferroni $P$ value correction). $\mathrm{Ho}=$ Observed heterozygosity, $\mathrm{He}=$ Expected heterozygosity, PIC=Polymorphic information contents, $\mathrm{HWE}=$ Hardy-Weinberg equilibrium used. In general, the mean number of alleles detected in each breed or genotype, and the expected heterozygosities are good indicators of the genetic polymorphism within the breed [7].

The mean value of the Ho for all loci in this study was higher than the overall mean value of He. Furthermore, the overall mean value of Ho was higher than the He value for the five studied breeds. These results indicate high genetic variability among studied breeds. Slightly lower Ho values were reported previously in Awassi sheep [15]. It was suggested that higher $\mathrm{Ho}$ or $\mathrm{He}$ values are highly correlated with higher values of PIC [15].

In this study, Awassi breed showed the highest average PIC value (0.59) while Romanov had the lowest PIC value (0.48). These results are lower than that reported in Kilakarsal sheep breed [14], but similar to those reported in Chokla thin-tailed sheep [16]. Mutation and selection jointly influence the level of polymorphism at microsatellite loci. The high PIC values in this study for the most of microsatellite markers used in this study indicate their suitability in biodiversity evaluation.

All markers in this study revealed a significant departure from HWE except for OARFCP304 marker. This may indicate migration or high mutation rate in microsatellites. It also could be due to artificial selection in the studied breeds [17]. Other factors that may affect HWE values include inbreeding, selection, mutation, and migration. Deviation from HWE at different marker loci has been reported previously in various breeds of sheep $[18,19]$.

Low value of the genetic distance between breeds indicates close relationship or common origin [20]. In this study, Charollais, Romanov, and Awassi breeds showed low genetic distances, while genetic distance was high between Suffolk and the other four studied breeds.

\section{Conclusion}

The genetic diversity and relatedness of local Awassi sheep to four exotic breeds in Jordan were investigated for the $1^{\text {st }}$ time in this study using microsatellite markers. The results indicate high genetic diversity

Table-3: Number of alleles (A), observed (Ho), and expected $\mathrm{He}$, Fi as a measure of heterozygote deficiency or excess, and polymorphic information contents (PIC) for eight microsatellites in Romanov, Charollais, and Suffolk, Awassi, and Assaf sheep breeds.

\begin{tabular}{|c|c|c|c|c|c|c|c|c|c|c|c|c|c|c|c|c|c|c|c|c|c|c|c|c|c|}
\hline \multirow[t]{2}{*}{ Locus } & \multicolumn{5}{|c|}{ Romanov } & \multicolumn{5}{|c|}{ Charollais } & \multicolumn{5}{|c|}{ Suffolk } & \multicolumn{5}{|c|}{ Awassi } & \multicolumn{5}{|c|}{ Assaf } \\
\hline & $\mathbf{A}$ & Ho & $\mathrm{He}$ & Fis & PIC & A & Ho & $\mathrm{He}$ & Fis & PIC & $\mathbf{A}$ & Ho & $\mathrm{He}$ & Fis & PIC & A & Ho & $\mathrm{He}$ & Fis & PIC & $\mathbf{A}$ & Ho & $\mathrm{He}$ & Fis & PIC \\
\hline ? & 3 & 1 & .5 & -0.9 & 0 & 3 & 1 & 0.6 & -0.6 & 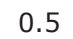 & 3 & 1 & 6 & -0.6 & & 3 & 1 & 0.6 & -0.6 & & 3 & 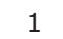 & 0.6 & 0.8 & \\
\hline LSTS11 & 3 & 1 & 0.6 & -0.6 & 0.5 & 3 & 1 & 0.6 & -0.6 & 0.5 & 3 & 1 & 0.6 & -0.6 & 0 & 3 & 1 & 0.7 & -0.5 & 0 & & 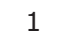 & 6 & 6 & \\
\hline OARCP34 & 2 & 1 & 0.5 & -1 & 0.4 & 3 & 1 & 0.6 & -0.7 & 0.5 & 2 & 1 & 0.5 & -1 & 0.4 & 3 & 1 & 0.7 & -0.5 & 0.6 & 3 & 1 & 0.6 & -0.6 & 0.5 \\
\hline OARFCP304 & 5 & 1 & 0.7 & -0.5 & 0.6 & 4 & 0.6 & 0.7 & 0.1 & 0.7 & 4 & 0.1 & 0.5 & 0.8 & & 5 & 0.9 & 0.8 & & 0 & 3 & 0.6 & 0.7 & 6 & 0.6 \\
\hline OARJMP58 & 4 & 0.8 & 0.6 & -0.4 & 0.5 & 4 & 0.7 & 0.7 & 0.0 & 0.7 & 3 & 0.7 & 0.7 & 0.0 & 0 & 5 & 0.9 & 0.8 & -0.1 & 0.7 & 4 & 0.9 & 0.7 & -0.4 & 0.6 \\
\hline OARAE 129 & 2 & 1 & 0.5 & -1 & 0.4 & 2 & 1 & 0.5 & -1 & 0.4 & 2 & 1 & 0.5 & -1 & 0.4 & 3 & 1 & 0.6 & -0.8 & 0.5 & 3 & 1 & 0.6 & -0.6 & 0.5 \\
\hline MAF214 & 4 & 1 & 0.7 & -0.4 & 0.6 & 3 & 1 & 0.6 & -0.6 & 0.6 & 3 & 1 & 0.6 & -0.6 & 0.5 & 4 & 1 & 0.7 & -0.4 & 0.7 & 4 & 1 & 0.7 & -0.4 & 0.7 \\
\hline MAF65 & 2 & 1 & 0.5 & -1 & 0.4 & 2 & 1 & 0.5 & -1 & 0.4 & 4 & 1 & 0.8 & -0.3 & 0.7 & 2 & 1 & 0.5 & -1 & 0.4 & 3 & 1 & 0.6 & -0.7 & 0.5 \\
\hline Average & 3 & 0.9 & 0.6 & & 0.5 & 3 & 0.9 & 0.6 & & 0.5 & 3 & 0.8 & 0.6 & & 0.5 & 3.5 & 0.9 & 0.7 & & 0.6 & 3.3 & 0.9 & 0.7 & & 0.6 \\
\hline
\end{tabular}

$\mathrm{Ho}=$ Observed heterozygosity, $\mathrm{He}=$ Expected heterozygosity, PIC=Polymorphic information contents, Fis=Fixation index 
Table-4: Matrix of Nei's standard genetic distances among sheep breeds.

\begin{tabular}{lccccc}
\hline Breed & Romanov & Charollais & Assaf & Awassi & Suffolk \\
\hline Romanov & 1 & 0.79 & 0.69 & 0.78 & 0.66 \\
Charollais & 0.24 & 1 & 0.72 & 0.79 & 0.67 \\
Assaf & 0.37 & 0.32 & 1 & 0.68 & 0.59 \\
Awassi & 0.25 & 0.24 & 0.39 & 1 & 0.77 \\
Suffolk & 0.42 & 0.41 & 0.53 & 0.27 & 1 \\
\hline
\end{tabular}

Nei's genetic identity (above diagonal) and genetic distance (below diagonal)

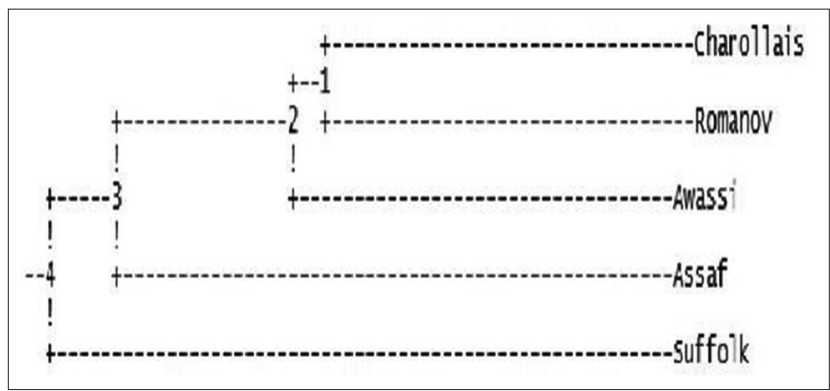

Figure-1: Unweighted pair group method with arithmetic mean dendrogram among Romanov, Charollais, and Suffolk, Awassi, and Assaf sheep breeds.

within the studied breeds. At the same time, a close relationship was found between Awassi and Romanov and Awassi and Charollais breeds, whereas distant relationships existed between Awassi and Assaf and between Assaf and Suffolk breeds. This information offers insight toward the genetic conservation of the studied breeds and a base on which breeding plans can be made.

\section{Authors' Contributions}

KJ: Designed the experiment and performed the laboratory work, the genetic and statistical analysis and manuscript writing. MA: Supervised the molecular experimental work, ZBI: Performed data interpretation and manuscript writing and revision, AMY: Collected samples and performed laboratory work, IAS: Help in the laboratory work. All authors read and approved the final manuscript.

\section{Acknowledgments}

This study was sponsored by the Deanship of Research at Jordan University of Science and Technology grant no. 0009/2013.

\section{Competing Interests} interests.

The authors declare that they have no competing

\section{References}

1. Abu Zanat, M.M., Mekdadi, H.A. and Tabbaa, M.J. (2005) Production systems of small ruminants in middle Badia of Jordan. Dirasat, 32: 205-213.

2. Jaber, L.S., Habre, A., Rawda, N., Abisaid, M., Barbour, E.K. and Hamadeh, S.K. (2004) The effect of water restriction on certain physiological parameters in Awassi sheep. Small Rum. Res., 54: 115-120.
3. Diez-Tascón, C., Littlejohn, R.P., Almeida, P.A. and Crawford, A.M. (2000) Genetic variation within the Merino sheep breed: Analysis of closely related populations using microsatellites. Anim. Genet., 31: 243-251.

4. Arranz, J.J., Bayón, Y. and San Primitivo, F. (2001) Differentiation among Spanish sheep breeds using microsatellites. Genet. Sel. Evol., 33: 529-542.

5. Arora, R. and Bhatia, S. (2004) Genetic structure of Muzzafarnagri sheep based on microsatellite analysis. Small Rum. Res., 54: 227-230.

6. Bozzi, R., Degl'Innocenti, P., Rivera Diaz, P., Nardia, L., Crovettia, A., Sargentinia, C. and Giorgettia, A. (2009) Genetic characterization and breed assignment in five Italian sheep breeds using microsatellite markers. Small Rum. Res., 85: 50-57.

7. Khan, M.A., Husain, S.S., Alam, M.R., Teneva, A., Han, J.L. and Faruque, M.O. (2009) Genetic relationship in different sheep populations of Bangladesh based on microsatellite markers. J. Bangladesh Agril. Univ., 7: 291-294.

8. Tariq, M.M., Bajwa, M.A., Jawasreh, K., Awan, M.A., Abbas, F., Waheed, A., Rafeeq, M., Wadood, A., Khan, K.U., Rashid, N., Atique, M.A. and Bukhari, F.A. (2012) Characterization of four indigenous sheep breeds of Balochistan, Pakistan by random amplified polymorphic DNAs. Afr. J. Biotechnol., 11: 2581-2586.

9. Ghazy, A., Mokhtar, S., Eid, M., Amin, A., Elzarei, M., Kizaki, K. and Hashizume, K. (2013) Genetic diversity and distances of three Egyptian local sheep breeds using microsatellite markers. Res. Zool., 3: 1-9.

10. Jawasreh, K., Al-Rawashdeh, I.M., Al-Majali, A., Talafha, H., Eljarah, A. and Awawdeh, F. (2011) Genetic relatedness among Jordanian local Awassi lines Baladi, Sagri, and Blackface and the black Najdi breed using RAPD analysis. Genom. Quant. Genet., 2: 31-36.

11. Yeh, F.C., Boyle, T., Rongcai, Y., Ye, Z. and Xian, J.M. (1999) Popgene, Version 1.31. A Microsoft Windows Based Freeware for Population Genetic Analysis. University of Alberta, Edmonton.

12. Marshall, T.C., Slate, J., Kruuk, L.E. and Pemberton, J.M. (1998) Statistical confidence for likelihood-based paternity inference in natural population. Mol. Ecol., 7: 639-655.

13. Nei, M. (1978) Estimation of average heterozygosity and genetic distance from a small number of individuals. Genet, 89: 583-590.

14. Radha, P., Sivaselvam, S.N., Kumarasamy, P. and Kumanan, K. (2011) Genetic diversity and bottleneck analysis of Kilakarsal sheep by microsatellite markers. Indian J. Biotechnol., 10: 52-55.

15. Al-Atiyat, R.M., Tabbaa, M.J., Salameh, N.M., Tarawneh, K.A., Al-Shmayla, L. and Al-Tamimie, H.J. (2012) Analysis of genetic variation of fat tailed-sheep in southern region of Jordan. Asian J. Anim. Vet. Adv., 7: 376-389.

16. Sodhi, M., Mukesh, M. and Bhatia, S. (2006) Characterizing Nali and Chokla sheep differentiation with microsatellite markers. Small Rum. Res., 65: 185-192.

17. Dashab, G.R., Aslaminejad, A., Nassiri, M., Esmailizadeh, A.K. and Saghi, D.A. (2011) Analysis of genetic diversity and structure of Buluchi sheep by microsatellite markers. Trop. Subtrop. Agroecosys., 14: 1047-1054.

18. Alvarez, I., Royo, L.J., Fernández, I., Gutiérrez, J.P., Gómez, E. and Goyache, F. (2004) Genetic relationships and admixture among sheep breeds from Northern Spain assessed using microsatellites. J. Anim. Sci., 82: 2246-2252.

19. Uzun, M., Gutiérrez-Gil, B., Arranz, J.J., Primitivo, F.S., Saatci, M., Kaya, M. and Bayón, Y. (2006) Genetic relationships among Turkish sheep. Genet. Sel. Evol., 38: 513-524.

20. Kawecka, A. and Katarzyna, P. (2011) Characteristics of the genetic structure of native sheep breeds. Ann. Anim. Sci., 11: 371-382. 